\title{
An Empirical Study of Outlook difference among Indian Students towards ICT for Demography and Educational Standards
}

\author{
Chaman Verma \\ Research Scholar, Deptt of CSE, JJT. University, Jhunjunu, Rajasthan (India) \\ chaman.verma@gmail.com \\ Sanjay Dahiya \\ Assistant Professor, Deptt. of CSE., Ch. Devi Lal State Institute of Engineering \& Tech. \\ PanniwalaMota, Sirsa, Haryana (India) \\ sanjaydahiyakkr@gmail.com \\ Yogesh Kumar Sharma \\ Associate Professor, Deptt. of CS., JJT. University, Jhunjunu, Rajasthan (India) \\ dr.yogeshkumar@yahoo.in
}

\begin{abstract}
Information and communication technology (ICT) is major backbone of Indian education system. Now days, the higher educational Institutions are using ICT based teaching and learning. Many of researchers, educators and students from the world are adapting sharply ICT in their educational life. Indian students have variety of thoughts towards ICT usage in their education. We have tried to explore the outlook difference among Indian students receiving higher education in Universities. More than five hundred students from six Universities located in Haryana and Punjab have participated in this study. This article is focusing on to find outlook difference among students towards ICT in relation to their locality and level of study. The statistically test like Z-test and T-test proves that educational standard and demography of students did not affect the outlook towards ICT awareness in higher education. This paper will support to investigators over the globe those are conducting their research on ICT awareness in higher educational institutions.
\end{abstract}

Keywords: - Demography, Study level, Significant, Outlook difference, T-test, Z-test

\section{Background}

Today's information is the key to knowledge. Now days it is very easy for ordinary man to access global information with the initiation of Information Technology (IT). In general sense Information includes text in fax and e-newspapers, images in video and television broadcasting, voice in mobile, video conferencing and data in computers. All the information can be digitized, transported, stored, retrieved, modified and then distributed (Siriginidi Subba Rao (2009)). Information Technology (IT) defines as distinct applications of computers and telecommunications equipments used for information collection, retrieval, storage, processing and presentation. It also covers various data processing functions likewise data storage, data retrieval, data recovery, data security, data transmission, data manipulation and databases etc. IT is mainly used in context of computers and networks (WI-fi or wired) and telecom equipment and services. It also covers other information distribution technologies such as television, mobiles and telephones. Now a day's many industries are related to information technology which are utilizing computers, software, electronics equipments, internet, Video-conferencing, telecom equipment. Kofi Ayebi-Arthur (2010) reported on Students' achievement in ICT, there was no difference between the mean scores of the undergraduate students and postgraduate students. With regards to Students' attitudes toward ICT both postgraduates and undergraduate students both showed positive attitudes towards ICT. He has also showed the relationship between attitudes and achievement there is a moderate correlation between undergraduate student's attitudes to ICT and their achievement in ICT where as among the 
postgraduate students there was a weak correlation between postgraduate student's attitudes to ICT and their achievement in ICT. Pei-Yu Wang (2013) stated that there is a significant difference in technology availability between rural and urban schools, including the number of interactive whiteboards, desktops in labs, notebooks, net books, and tablet computers. There was also a difference in teacher overall high-tech integration level between rural and urban schools. T-test comparisons between the urban and rural schools were conducted to examine the difference in the student attitudes, including anxiety, enjoyment, and self-efficacy. No significant difference was found in terms of these items between rural and urban students. V. Sharmila (2015) concluded that the there is significant difference in the aptitude towards ICT of Male and female B.Ed. Trainees but there is no significant difference in the aptitude towards ICT of rural and urban area B.Ed. Trainees. They also described that there is significant difference in aptitude towards ICT of arts and science group B.Ed. Trainees. They have proved that there is no significant difference in the aptitude towards ICT of Nuclear and Joint family B.Ed. Trainees. They also found meaningful variations in aptitude towards ICT of Internet users and non users B.Ed. Trainees and it is identified that the Internet users B.Ed. Trainees have more aptitude towards ICT than the non users B.Ed. Trainees. Mohit Dixit and Manpreet Kaur (2015) have found meaningful difference between urban and rural teachers at 5\% level and they have also revealed that locality variable has affected attitude of teachers towards ICT teaching. S. Francisca (2012) found significant difference between arts and science trainees in their ICT competencies. She has also found significant difference between UG and PG qualified trainees in their ICT competency. Trainees with PG qualification are better competent than UG trainees. She explored the trainees of aided colleges and self finance colleges significantly differ in their competencies in Word Processing and Internet knowledge. Trainees of aided colleges have better competencies than the trainees of self financing colleges. Ying-Tien Wu and Chin-Chung Tsai (2006) found grade level affects the students' attitudes toward the Internet mean graduate students posses positive attitude and also observed Internet self-efficacy related with internet attitude also. Md. Abdullah Al Mahmud (2011) also revealed that the students exhibited positive attitudes toward the Internet irrespective of gender, again in contradiction to most other findings. Zeynep Koyunlu Ünlü et. al., (2014) concluded that significant difference in favor of urban students in the overall scores as well as the scores in the following subscale scores: "using the Internet in social interactions", "using the Internet in communication", "using the Internet in information sharing", and "liking the use of the Internet in education". They have found no significant difference between rural and urban students for other sub dimensions, i.e. using the Internet in education and research. Makewa L. N, et al., (2014) have evaluated ICT-Based Education and student Behavioral Change at University of Arusha, Tanzania. They have discovered significant difference among educators in relation to educational level, gender using t-test and ANOVA. They have concluded that gender variable has not affected the application of ICT in teaching-learning transaction by University of Arusha educators by applied Ttest. They have also revealed that there is no significant difference in the integration of ICT in teaching-learning transaction by educators categorized according to their educational qualifications. They have also concluded that no significant difference in the perception of usefulness of ICT in teaching-learning transaction by University educators categorized according to gender and educational level.

\section{Objective and Hypotheses}

The key objective of this study is to evaluate the outlook difference among Indian students towards ICT awareness in relation to their demography and education standards who are studying in higher educational institutions. To examine the outlook difference among students for their Locality or 
demography and Educational Standards or Study level, we assumed two null and their corresponding null hypotheses mentioned below:

H01- There is no significant difference between outlook of rural and urban students towards ICT awareness in higher education.

HA1- There is a significant difference between outlook of rural and urban students towards ICT awareness in higher education.

H02- There is no significant difference between outlook of Undergraduate and Postgraduate students towards ICT awareness in higher education.

HA1- There is a significant difference between outlook of Undergraduate and Postgraduate students towards ICT awareness in higher education.

\section{Design and Methodology}

The present study includes quantitative and an empirical method. A descriptive survey method with stratified random sampling technique is applied to collect primary data of 560 samples with the help of self made structured questionnaire. The Participants were asked to write their outlook into the framed questionnaire by keeping the variables and objective in their mind. This section is further divided into three subsections in order to understand the concept of research design and methodology.

\subsection{Variables and Population}

Total 35 dependent variables are considered as discussed in previous chapters. In present study, 35 dependant and 4 independent variables are considered. The following Fig. 1.1 shows schematic view of both type of variables dependant and independent. It shows the dependency of 4 independent variables on 35 dependent variables.

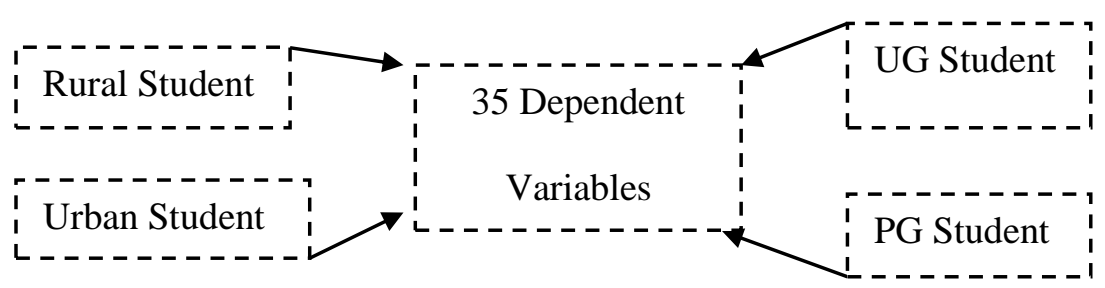

Fig 1.1 Dependency of Variables

(Source: Author)

The above Fig. 1.1 shows the four independent variables named rural student, urban student, UG student and PG student.

Table 1.1 Population of UG-PG and Rural-Urban Student

\begin{tabular}{|c|c|c|c|c|}
\hline Variables & Frequency & Total & Percentage & Total \\
\hline Rural Student & 279 & 560 & 49.8 & \multirow{2}{*}{100} \\
\cline { 1 - 2 } Urban Student & 281 & & 50.2 & \\
\hline UG Student & 286 & \multirow{2}{*}{560} & 51.1 & \multirow{2}{*}{100} \\
\cline { 1 - 2 } \cline { 4 - 5 } PG Student & 274 & & 49.9 & \\
\hline
\end{tabular}

(Source: Author) 
From Table 1.1 shows that out of total 560 students, 279 rural students and 281 urban students has took part in study. The count of UG students and PG students is 286 and 274 respectively.

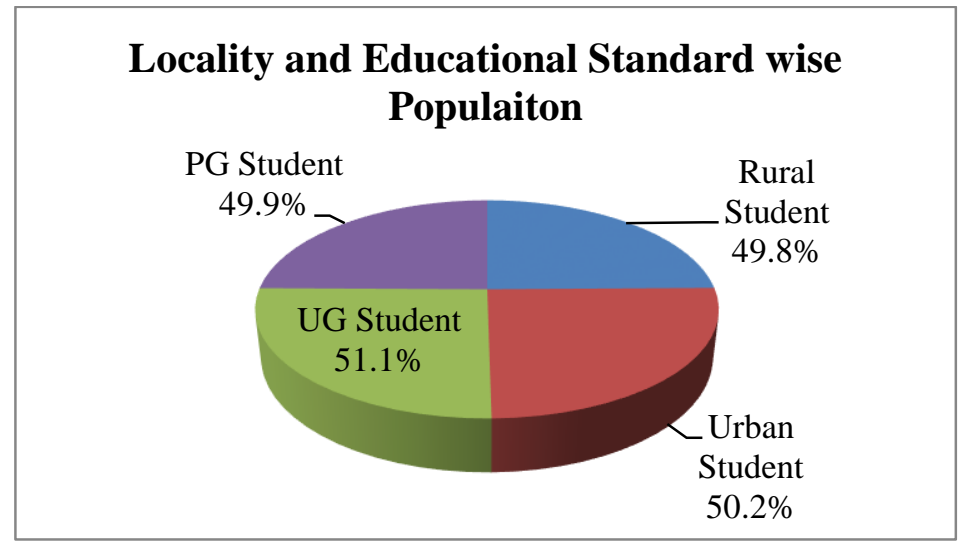

Fig 1.2 Population under Variables (Source: Author)

The Fig. 1.2 shows the total percentage of participants under assumed variables. There are $49.8 \%$ rural student and 50.2\% are urban student participated in this study. Another side, there are 51.1\% students from UG (Undergraduate) and $49.9 \%$ are from PG (postgraduate) background. The present study is conducted on six Universities located in Haryana and Punjab state of India. Total 560 students have participated in this research. There is 02 private and 01 Government University is from Punjab and 02 Government and 01 private University is from Haryana state is considered. All the participants are belongs to various domains such as engineering, arts, management and science.

\subsection{Framing of Questionnaire and Validation}

In order to collect samples, a self made survey form is designed which is used at five point Likert scale to obtain numeric scores of students. The designed questionnaire is divided into five major parts: Availability, Usability, Problem, Solution and Opportunity. There are 35 dependant variables are used which sense the ICT Awareness in higher education. The validation of tool is checked by item analysis test which is firstly adapted by Kelley's in 1939. We found only 35 variables are having good status out of 70 .

\subsection{Statistical Techniques}

Differential analysis is used to evaluate the collected data. The assumed null hypotheses are tested with T-test, Z-test and Single factor ANOVA. The descriptive analysis is also applied like frequency measure; percentage count and mean. The data analysis package named Analysis Toolpack and Analysis Toolpack-VBA in Microsoft Excel are used appropriately.

\section{Results and Discussions}

This section explores the findings of the research. In order to examine the outlook difference among student's thoughts towards ICT awareness in higher education, we applied T-test and Z-test at various significant levels to find significant mean difference. Further, one way ANOVA is also applied to test group mean of students. 


\subsection{Demography Wise Mean Difference}

This sections test our first null hypothesis H01 "There is no significant difference between outlook of rural and urban students towards ICT awareness in higher education". We have explored significant difference between opinions of students for their demographical characteristics. To find out statistically mean difference between rural students and urban students, we have applied here T-test at various significant levels for 68 degree of freedom. We have also applied Z-test at various level of confidence $(\alpha)$ for 68 degree of freedom for explore mean difference between rural and urban students.

Table 1.2 T-Test on H01 at Various Significant Levels ( $\alpha$ )

\begin{tabular}{|c|c|c|c|}
\hline $\begin{array}{c}\text { Calculated } \\
\text { T-Value }\end{array}$ & $\begin{array}{c}\text { Observed } \\
\text { T-Value }\end{array}$ & $\begin{array}{c}\text { Level } \\
\text { of Significance }(\alpha \\
)\end{array}$ & $\begin{array}{c}\text { Failed to Accept } \\
\text { or Failed to Reject }\end{array}$ \\
\hline \multirow{3}{*}{0.64} & 2.0 & 5 & \multirow{3}{*}{ Failed to Reject } \\
\cline { 2 - 3 } & 2.09 & 4 & \\
\cline { 2 - 3 } & 2.22 & 3 & \\
\cline { 2 - 3 } & 2.38 & 2 & \multicolumn{1}{|c}{} \\
\cline { 2 - 3 } & 2.65 & 1 & \\
\hline
\end{tabular}

(Source: Author)

Data from Table 1.2 evident that at various level of significant $(5,4,3,2,1)$ the calculated t-value is same which is 0.64 , but observed $t$-values are increasing $(2.0,2.09,2.22,2.38,2.65)$. The calculated $t-$ value is not significant at all levels. There is no significant difference between mean of rural student and urban student. The calculated t-value is smaller than the observed t-values at all confidence levels. Hence null hypothesis H01 "There is no significant difference between outlook of rural and urban students towards ICT awareness in higher education", is failed to reject. Therefore, there is no significant difference between mean of rural students and urban students towards ICT in higher education. At another side the alternate hypothesis HA1"There is a significant difference between outlook of rural and urban students towards ICT awareness in higher education" is failed to accept. The T-Test at all significant levels concluded that locality did not affect the outlook of students towards ICT. The findings of Pei-Yu Wang (2013) are consistent with our results.

The $\mathrm{Z}$-test is also applied here in order to test first hypothesis $\mathrm{H} 01$ "There is no significant difference between outlook of rural and urban students towards ICT awareness in higher education". The Table 1.3 shows the results found after evaluation of hypothesis H01 at various levels significance for 68 degree of freedom.

Table 1.3 Z-Test on H031 at Various Significant Levels $(\alpha)$

\begin{tabular}{|c|c|c|c|c|c|}
\hline Df \& $\alpha$ & $\alpha=5 \%$ & $\alpha=4 \%$ & $\alpha=3 \%$ & $\alpha=2 \%$ & $\alpha=1 \%$ \\
\cline { 2 - 6 } & \multicolumn{5}{|c|}{$\mathrm{Df}=68$} \\
\hline $\begin{array}{c}\text { Z Values } \\
\begin{array}{c}\text { Calculated Z- } \\
\text { value }\end{array}\end{array}$ & \multicolumn{4}{|c|}{0.64} \\
\hline $\begin{array}{c}\text { Observed Z- } \\
\text { value }\end{array}$ & 1.96 & 2.05 & 2.17 & 2.33 & 2.58 \\
\hline Significant at $\alpha$ & \multicolumn{5}{|c|}{ Not Significant at all levels } \\
\hline
\end{tabular}

(Source: Author) 
Table 1.3 infers that applied Z-test on hypothesis H01 "There is no significant difference between outlook of rural and urban students towards ICT awareness in higher education" at various confidence levels $(\alpha)$ for 68 degree of freedom (df). The calculated Z-value is smaller than the observed Z-values $(0.64<1.96,0.64<2.05,0.64<2.17,0.64<2.33,0.64<2.58)$ at various level of significant $(5,4,3,2,1)$. The calculated Z-value is not significant at all levels. There is no significant difference between mean of rural students and urban students. The calculated Z-value is smaller than the observed Z-values at all confidence levels. Hence null hypothesis H031 "There is no significant difference between outlook of rural and urban students towards ICT awareness in higher education", is failed to reject. At another side alternate hypothesis HA1"There is a significant difference between outlook of rural and urban students towards ICT awareness in higher education" is failed to accept here. The Z-Test at all significant levels proved locality of students did not impact on difference between rural and urban student towards ICT. The outcomes of this test are matches with results of (V. Sharmila (2015)) but contradictory with findings of (Mohit Dixit and Manpreet Kaur (2015)).

\subsection{Education Standard Wise Mean Difference}

Here we investigated outlook difference among students according to their educational standards. We have investigated significant difference between outlook of undergraduate (UG) students and postgraduate (PG) students towards ICT in higher education. To calculate mean difference between UG students and PG students, we have applied both T-test and Z-Test at various significant levels for 68 degree of freedom. We have tested our second hypothesis H02 "There is no significant difference between outlook of Undergraduate and Postgraduate students towards ICT awareness in higher education" at various confidence level using student T-test.

Table 1.4: T-Test on H032 at Various Significant Levels $(\alpha)$

\begin{tabular}{|c|c|c|c|}
\hline $\begin{array}{c}\text { Calculated T } \\
\text { Vale }\end{array}$ & $\begin{array}{c}\text { Observed } \\
\text { T-Value }\end{array}$ & $\begin{array}{c}\text { Level of Significance } \\
(\alpha)\end{array}$ & $\begin{array}{c}\text { Failed to Accept or } \\
\text { Failed to Reject }\end{array}$ \\
\hline \multirow{3}{*}{0.29} & 2.0 & 5 & \multirow{3}{*}{ Failed to Reject } \\
\cline { 2 - 3 } & 2.09 & 4 & \\
\cline { 2 - 3 } & 2.22 & 3 & \\
\cline { 2 - 3 } & 2.38 & 2 & \\
\cline { 2 - 3 } & 2.65 & 1 & \\
\hline
\end{tabular}

(Source: Author)

The above Table 1.4 shows that at various level of significant $(5,4,3,2,1)$ the calculated t-value is same which is 0.29 , but observed $t$-values are increasing $(2.0,2.09,2.22,2.38,2.65)$. The calculated $t-$ value is not significant at all levels. There is no significant difference between mean of UG students and PG students. The calculated $t$-value is smaller than the observed $t$-values at all confidence levels. Hence null hypothesis $\mathrm{H} 02$ "There is no significant difference between outlook of Undergraduate and Postgraduate students towards ICT awareness in higher education", is failed to reject and its corresponding alternate hypothesis HA2 "There is a significant difference between outlook of Undergraduate and Postgraduate students towards ICT awareness in higher education" is failed to accept. Therefore, there is no significant difference between opinion of UG students and PG students towards ICT. S. Francisca (2012) found there is significant difference between UG and PG qualified trainees in their ICT competency. Trainees with PG qualification are better competent than UG trainees. But our outcomes of this test are not consistent with the results of S. Francisca (2012) and and Kofi Ayebi-Arthur (2010). 
For hypothesis H02 "There is no significant difference between outlook of undergraduate and postgraduate students towards ICT awareness in higher education" Z-test at various levels of significance $(\alpha)$ for 68 degree of freedom (df) is applied. The following Table shows the findings of Z-test.

Table 1.5: Z-Test on H032 at Various Significant Levels ( $\alpha$ )

\begin{tabular}{|c|c|c|c|c|c|}
\hline Df \& $\alpha$ & $\alpha=5 \%$ & $\alpha=4 \%$ & $\alpha=3 \%$ & $\alpha=2 \%$ & $\alpha=1 \%$ \\
\cline { 2 - 5 } & \multicolumn{5}{|c|}{$\mathrm{Df}=68$} \\
\hline $\begin{array}{c}\text { Z Values } \\
\begin{array}{c}\text { Calculated Z- } \\
\text { value }\end{array}\end{array}$ & 1.96 & 2.05 & 2.17 & 2.33 & 2.58 \\
\hline $\begin{array}{c}\text { Observed Z- } \\
\text { value }\end{array}$ & \multicolumn{5}{|c|}{0.30} \\
\hline Significant at $\alpha$ & \multicolumn{5}{|c|}{ Not Significant at all levels } \\
\hline
\end{tabular}

(Source: Author)

Data from Table 1.5 infers that applied Z-test on hypothesis H02 "There is no significant difference between outlook of Undergraduate and Postgraduate students towards ICT awareness in higher education" at various confidence levels $(\alpha)$ for 68 degree of freedom (df). The calculated Z-value is smaller than the observed Z-values $(0.30<1.96,0.30<2.05,0.30<2.17,0.30<2.33,0.30<2.58)$ at various level of significant $(5,4,3,2,1)$. The calculated $Z$-value is not significant at all levels. There is no significant difference between mean of UG students and PG students. The calculated Z-value is smaller than the observed Z-values at all confidence levels. Hence null hypothesis H02 "There is no significant difference between outlook of Undergraduate and Postgraduate students towards ICT awareness in higher education", is failed to reject and its corresponding alternate hypothesis HA2 "There is a significant difference between outlook of Undergraduate and Postgraduate students towards ICT awareness in higher education" is failed to accept. Therefore, educational standards of students did not impact opinions of students towards ICT. The results of this test are satisfying the outcomes of (Kofi Ayebi-Arthur (2010)).

\subsection{One-Way ANOVA}

ANOVA is also called analysis of variance. A single factor or one-way ANOVA is used to explore whether the means of several populations are all equal or not. It uses where we have more than two groups and need to find significant difference in mean values in two ways: between groups and within groups. Here we have applied single factor ANOVA at 5\% significant levels.

Table 1.6: Summary of ANOVA Rural-Urban and UG-PG group

\begin{tabular}{|c|c|c|c|c|}
\hline Groups & Count & Sum & Average & Variance \\
\hline Rural student & 35 & 127.38 & 3.64 & 0.1 \\
\hline Urban student & 35 & 125.36 & 3.58 & 0.2 \\
\hline UG student & 35 & 126.90 & 3.63 & 0.2 \\
\hline PG student & 35 & 125.96 & 3.60 & 0.1 \\
\hline
\end{tabular}

(Source: Author) 
Table 1.6 explores the summary of four groups. It also shows total count of 35 variables, sum of variances, average, calculated mean scores for groups and variances. It is transparent from the above data that mean values of each group are almost equal if we apply round off operation. Hence, summary table states that there is no significant mean difference among groups.

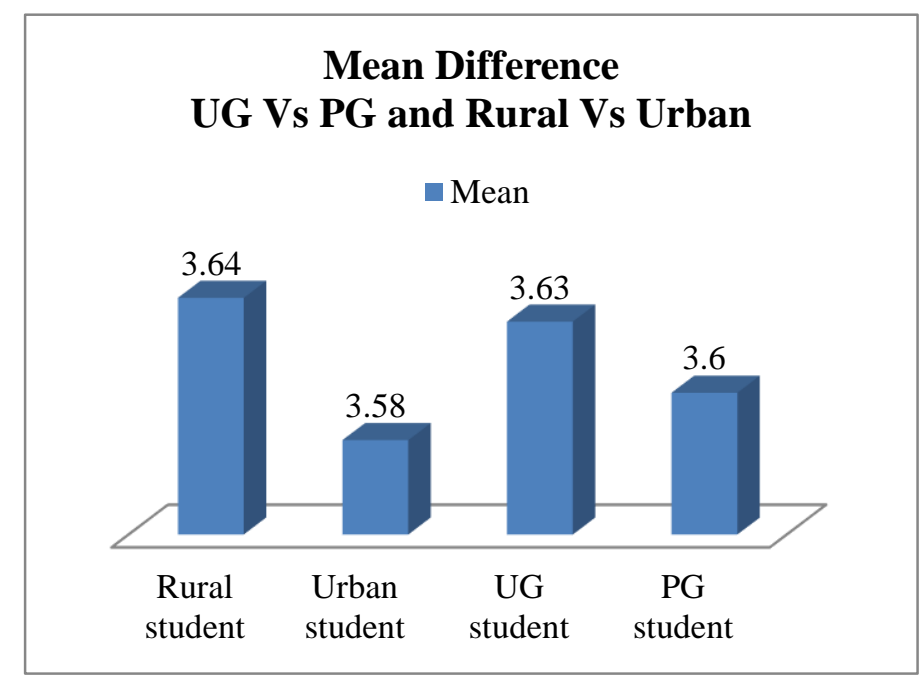

Fig 1.3 Mean Difference towards ICT, (Source: Author)

The above Fig. 1.3 shows that there calculated mean for students are not identical in relation to their demography and educational standards. Even though, they have positive attitude towards towards ICT usage in their educational life. There is mean difference between urban and rural student is 0.06 (3.643.58). The rural students won from urban students regarding their positive attitude towards technological usage. We have also found minor mean difference between students in respect of their study level which is calculated 0.03 (3.63-3.6). We concluded that there is no meaningful mean difference between students for their educational standard (study level) and demography (locality) towards Information and communication technology.

Table 1.7: One Way ANOVA on UG-PG and Rural-Urban Students

\begin{tabular}{|c|c|c|c|c|c|c|}
\hline $\begin{array}{c}\text { Source of } \\
\text { Variation }\end{array}$ & SS & df & MS & F & P-value & F -crit \\
\hline Between Groups & 0.07 & 3 & 0.02 & 0.16 & 0.92 & 2.67 \\
\hline Within Groups & 19.84 & 136 & 0.15 & & & \\
\hline Total & 19.91 & 139 & & & & \\
\hline
\end{tabular}

(Source: Author)

Table 1.7 evident that calculated $F$ value is 0.16 , is smaller than Critical $F$ value which is $2.67(2.67>0.16)$. Hence mean values of all groups named rural student, urban student, PG student and UG student are almost equal. It is found identical at 5\% level. Therefore, there is no significant difference between group's means. It has been concluded that student's mean scores are not differing for their educational standards and demography.

\section{Conclusion}

This research explores that there is no variation between mean of rural students and urban students. The locality or demography characteristics did not affect the opinions of students of Punjab and Haryana towards ICT. The cause is not availability of ICT resources in remote areas of states. It is also concluded that educational standard of students did not make any impact on students' opinions 
towards ICT. We found no variation difference between opinion of UG and PG students towards information and communication technology. The reason is postgraduate students have broad attitude as compare to undergraduate students.

We found variance difference between rural and urban students towards variables such as easy access of ICT resources, ICT encourages research and project development, Need to increase the latest ICT infrastructure, Student feel more professional, motivate, confident while using ICT resources and ICT reduce the cost for information exchange. At another side, there is no locality wise significant difference among students towards rest of variables likewise availability of Wi-fi campus, sufficient bandwidth, E-library, E-journals/ E-contents; Reliability of ICT tools in R\&D, exchange the research information, Time consuming, lack of training, use of Planning and Management, in learn the lecture/lesson from other institutions experts through video conferencing; problem of Time consuming, Unfriendly ICT tools/software's; needs to increase Internet bandwidth, latest ICT infrastructure, E-journals/ E-contents. It is also found scatteredness in responses of UG and PG students towards ICT is used to exchange the research information, ICT used adequately in teaching, learning and research activities, Enhance Internet bandwidth, Need for training/workshop to learn ICT resources and ICT role in admission and examination.

Findings of this study explore the current scenario of ICT awareness in six Universities of Punjab and Haryana. This study has been conducted to test the statistically significant difference in outlook of students towards ICT awareness for availability, usability, problem and solution in relation to various aspects like locality or demography and educational standards or study level. We have faced many problems during this course of study regarding collection of valuable data and information towards information technology awareness among stakeholders of Universities under study. It was very complex for the investigator to obtain accurate suggestion about current usability and availability of ICT resources in Universities under study. It was also a big challenge for researcher to examine the problem faced by stakeholders and provides remedial facts regarding found issues in concerned Institutions. We have found many true facts which are directly influenced by the ICT awareness of stakeholders according to their demography and educational standards. This research explored the real problem facing by stakeholders in ICT use in institutions and their possible remedial which are feasible to enhance the level of ICT in the higher educational institutions. It is concluded that there is no significant difference between mean of rural students and urban students towards ICT in higher education. Therefore, demography did not influence the outlook of students towards ICT awareness in higher education. Furthermore, it is also revealed that study level or educational standard did not affect outlook of students of higher educational institutions. We found no meaningful outlook difference between undergraduate and postgraduate students. This study is valuable for the Indian Government and state administrations to be aware about the current state of ICT in Universities. This study will helpful for future researchers and investigators to do more work by using another possible variable such as age, occupation, stream and gender. The outcomes of present study show clear roadmap for ICT policy makers and Institutional management of Universities under study to provide latest technology and quality based education.

\section{Declaration of Conflicting Interests}

The author(s) affirmed no competing interest in relation to this research, authorship, and/or publication of this article. 


\section{Funding}

The author(s) received no financial support for the present research and/or authorship of this article.

\section{Acknowledgments}

This research paper is a part of of Ph.D thesis which is currently being conducted by the corresponding author. The author would like to thank administrations of all participated Universities for providing such a wonderful support to completion of this research. Chaman Verma has collected the samples and analyzed the data and found results after peer review of concerned literature. Finally he drafted the manuscript. Sanjay Dahiya and Yogesh Kumar Sharma has critical reviewed the manuscript especially results of manuscript. All the author(s) have read and approved the final manuscript before submission.

\section{References}

1. Kofi Ayebi-Arthur (2010).Relationship between students' attitudes toward ICT and their achievement in ICT at the University of Cape Coast. International Journal of Basic Education.1:1-11.

2. Md. Abdullah Al Mahmud (2011). Students' Attitudes towards Internet: a study on Private Universities of Bangladesh 2011. European Journal of Business and Management. 3(6).

3. Mohit Dixit and Manpreet Kaur (2015). Attitude of Teachers Trainees towards ICT Teaching. International Journal of Pure and Applied Researches. 1(1):169-174.

4. Makewa L. N, et al., (2014). ICT-Integration in Higher Education and Student Behavioral Change: Observations at University of Arusha, Tanzania. American Journal of Educational Research. 2(11-A): 30- 38.

5. Pei-Yu Wang (2013). Examining the Digital Divide between Rural and Urban Schools: Technology Availability, Teachers' Integration Level and Students' Perception. Journal of Curriculum and Teaching.2(2):127-139.

6. S. Francisca (2012). ICT Competency of Teacher Trainees. International Interdisciplinary Research Journal. 2(1):47-57.

7. Siriginidi Subba Rao (2009).Role of ICTS in India Rural Communities. Journal of Community Informatics.5(1).

8. V. Sharmila (2015). B.ed.Trainees aptitude towards ICT in Cuddalore district. International Multidisciplinary Research Journal. 3(4):1-4.

9. Ying-Tien WU and Chin-Chung Tsai, (2006). University Students' Internet Attitudes and Internet Self-Efficacy: A Study at Three Universities in Taiwan. Cyber psychology \& Behavior. 9(4).

10. Zeynep Koyunlu Ünlü et. al., (2014).A comparison of the attitudes of rural and urban secondary school students towards the use of the internet. World Journal on Educational Technology. 6(2):192-202. 